\title{
Resurgence of Sleeping Sickness in Tambura County, Sudan
}

Anne Moore

Michaleen Richer

Mario Enrile

Edward Losio

Jacquelin Roberts

See next page for additional authors

Tell us how you used this information in this short survey.

Follow this and additional works at: https://digitalcommons.unmc.edu/coph_epidem_articles

Part of the Epidemiology Commons

\section{Recommended Citation}

Moore, Anne; Richer, Michaleen; Enrile, Mario; Losio, Edward; Roberts, Jacquelin; and Levy, Deborah A., "Resurgence of Sleeping Sickness in Tambura County, Sudan" (1999). Journal Articles: Epidemiology. 104. https://digitalcommons.unmc.edu/coph_epidem_articles/104

This Article is brought to you for free and open access by the Epidemiology at DigitalCommons@UNMC. It has been accepted for inclusion in Journal Articles: Epidemiology by an authorized administrator of DigitalCommons@UNMC.For more information, please contact digitalcommons@unmc.edu. 


\section{Authors}

Anne Moore, Michaleen Richer, Mario Enrile, Edward Losio, Jacquelin Roberts, and Deborah A. Levy 


\title{
RESURGENCE OF SLEEPING SICKNESS IN TAMBURA COUNTY, SUDAN
}

\author{
ANNE MOORE, MICHALEEN RICHER, MARIO ENRILE, EDWARD LOSIO, JACQUELIN ROBERTS, \\ AND DEBORAH LEVY \\ Division of Parasitic Diseases, National Center for Infectious Diseases, Centers for Disease Control and Prevention, \\ Atlanta, Georgia; International Medical Corps, Nairobi, Kenya; CARE International, Nairobi, Kenya; \\ Sudanese Relief and Rehabilitation Agency, Tambura, Sudan
}

\begin{abstract}
Endemic foci of human African trypanosomiasis are present in southern Sudan. In 1996 and 1997, trypanosomiasis increased sharply in Tambura County. To define the magnitude and geographic distribution of the outbreak, we conducted a prevalence survey using population-based cluster sampling in 16 villages: 1,358 participants answered questions about routine activities and tsetse fly contact and received serologic testing. Seroprevalence in the surveyed area was $19.4 \%$ (95\% confidence interval $=16.9 \%, 21.8 \%)$. We confirmed infection in $66 \%$ of seropositive persons who received one parasitologic examination and in $95 \%$ of those who had serial examinations of lymph node fluid and blood. Activities related to the civil war, such as temporary migration, were not associated with seropositive status. Since the previous population screening in 1988, the trypanosomiasis prevalence increased two orders of magnitude, and the proportion of villages affected increased from $54 \%$ to $100 \%$. Our results suggest that there may be 5,000 cases in Tambura County. The absence of trypanosomiasis control for nearly a decade is a factor in the resurgence of the disease.
\end{abstract}

Human African trypanosomiasis (sleeping sickness), caused by Trypanosoma brucei gambiense, remains a significant public health problem in sub-Saharan Africa. The threat is most serious in central Africa, where Angola, Democratic Republic of Congo, and Uganda have faced epidemics of the disease in recent years. ${ }^{1-4}$

Endemic foci of human trypanosomiasis are present in southern Sudan. ${ }^{2}$ During the 1980s, a bilateral Belgian-Sudanese control program limited the incidence of trypanosomiasis in the Sudan province of Western Equatoria. However, control activities collapsed in 1990 when fighting in the civil war intensified. In late 1994, the International Medical Corps (IMC) began passive surveillance for trypanosomiasis in Tambura County. The county hospital admitted 87 cases of sleeping sickness in 1996, a 4-fold increase above the number treated the previous year. More than $60 \%$ of the trypanosomiasis patients were residents of Ezo, in the southwestern part of Tambura County, bordering the Central African Republic and the Democratic Republic of Congo. In early 1997 , parasitologically confirmed infection was found in $103(23 \%)$ of 423 patients screened for trypanosomiasis at the Ezo Health center. To more accurately define the magnitude and geographic distribution of the outbreak of human trypanosomiasis in Tambura County, we conducted a population-based prevalence survey in Ezo and adjacent areas.

\section{METHODS}

Survey method. In May-July, 1997, a multistage cluster sampling design based on the method of Turner and others ${ }^{5}$ was used to survey an area of approximately 600 square miles in southwestern Tambura County. The surveyed area included 16 towns and villages with a total population of 25,000, based on a 1996 census conducted by CARE International. Each village was divided into sectors of similar size (40-60 persons). In our survey, a sector comprised all persons governed by an individual headman, excluding children 5 years old or younger. The number of randomly selected sectors sampled within a village was weighted according to population, with a total of 1,358 participants in 34 sectors. This investigation adhered to the policies of the Centers for
Disease Control and Prevention with regard to human subjects.

Epidemiologic data. Participation in the survey was voluntary. Each participant completed an interview in which demographic data were collected and questions were asked regarding present symptoms and previous trypanosomiasis screening and treatment. Participants were asked about whether they performed specific activities that may have placed them at risk for contact with tsetse flies, whether these activities were performed regularly, and whether tsetse flies were often observed at the activity location. Information was requested about daily activities (e.g., collecting water, cultivating) and possible risk factors related to the ongoing civil war (e.g., fleeing temporarily to other areas, hiding in local forests).

Laboratory methods. Serum was obtained from blood collected by fingerstick and was screened for the presence of antibodies to T. $b$. gambiense using the card agglutination test for trypanosomiasis (CATT-T. $b$. gambiense; Institute of Tropical Medicine, Antwerp, Belgium). Microscopic detection of trypanosomes in lymph node fluid or blood was used to confirm infection in seropositive participants.

Patient follow-up. Seropositive survey participants received follow-up medical care at Tambura County Hospital or Ezo Health Center. Patients with confirmed trypanosomiasis underwent examination of cerebrospinal fluid (CSF). Late-stage disease was defined by CSF containing trypanosomes, elevated protein $(>40 \mathrm{mg} \%)$, or $>5$ white blood cells/ $\mu$ l. Patients with early-stage disease (hemolymphatic) were treated with pentamidine, and patients with late-stage disease (central nervous system [CNS] involvement) were treated with melarsoprol using three series of three daily injections. ${ }^{2}$ Seropositive participants whose infections were not confirmed during the survey and who had normal CSF received one or more monthly follow-up parasitologic examinations. In our protocol, seropositive patients with abnormal CSF but without parasitologically confirmed infection received treatment with melarsoprol.

Statistical methods. Statistical analysis was done using SAS software (version 6.12; SAS Institute, Inc., Cary, NC) 
TABLE 1

Association between Trypanosoma brucei gambiense seropositivity and demographic characteristics or clinical symptoms among residents of Tambura County, Sudan, 1997

\begin{tabular}{|c|c|c|c|c|}
\hline & Number & Seropositive (\%) & $\mathrm{RR}^{*}$ & $95 \% \mathrm{CI} \dagger$ \\
\hline \multicolumn{5}{|l|}{ Demographics } \\
\hline Survey population & 1,358 & 19.4 & - & $16.9,21.8$ \\
\hline Male & 731 & 19.2 & Referent & \\
\hline Female & 627 & 19.6 & 1.01 & $0.96,1.06$ \\
\hline \multicolumn{5}{|l|}{ Age group (years) } \\
\hline $6-9$ & 65 & 7.7 & 0.40 & $0.16,0.98$ \\
\hline $10-19$ & 369 & 18.7 & 0.97 & $0.68,1.38$ \\
\hline $20-29$ & 275 & 17.8 & 0.92 & $0.66,1.28$ \\
\hline $30-39$ & 213 & 19.2 & 1.00 & $0.68,1.46$ \\
\hline $40-49$ & 191 & 28.8 & 1.49 & $1.06,2.09$ \\
\hline $50-59$ & 126 & 16.7 & 0.86 & $0.65,1.14$ \\
\hline$\geq 60$ & 119 & 19.3 & Referent & \\
\hline \multicolumn{5}{|l|}{ Village of residence } \\
\hline Andari & 80 & 5.0 & & $2.6,7.5$ \\
\hline Bariguna & 160 & 8.3 & & $5.7,10.6$ \\
\hline Ezo & 440 & 37.0 & & $31.6,42.5$ \\
\hline Mangbangau/Madoro & 160 & 13.1 & & $10.7,15.7$ \\
\hline Source Yubu & 79 & 21.5 & & $19.1,24.0$ \\
\hline Resided away from home & 190 & 13.2 & 0.63 & $0.4,1.0$ \\
\hline Within Tambura County & 72 & 9.7 & 0.47 & $0.2,1.1$ \\
\hline Elsewhere, southern Sudan & 26 & 15.4 & 0.74 & $0.2,2.3$ \\
\hline Central African Republic & 59 & 13.6 & 0.65 & $0.3,1.4$ \\
\hline Democratic Republic of Congo & 37 & 10.8 & 0.52 & $0.2,1.6$ \\
\hline \multicolumn{5}{|l|}{ Clinical history/symptoms } \\
\hline Screened, treated before 1994 & 31 & 32.3 & 1.70 & $1.12,2.57$ \\
\hline Family member treated & 234 & 23.5 & 1.20 & $1.03,1.55$ \\
\hline Fever & 450 & 20.8 & 1.11 & $0.93,1.34$ \\
\hline Fever $>1$ month $($ mean $=3.2)$ & 32 & 44.1 & 2.30 & $1.59,3.48$ \\
\hline Pruritis & 251 & 19.4 & 1.00 & $0.76,1.32$ \\
\hline Myalgia/arthralgia & 246 & 28.9 & 1.67 & $1.22,2.29$ \\
\hline $\begin{array}{l}\text { Myalgia/arthralgia }>1 \text { month } \\
\quad(\text { mean }=6.9)\end{array}$ & 99 & 36.4 & 2.00 & $1.35,3.02$ \\
\hline Mood/sleep disturbance & 12 & 25.0 & 1.29 & $0.31,5.42$ \\
\hline Edema & 9 & 55.6 & 2.90 & $1.55,5.45$ \\
\hline
\end{tabular}

$* \mathrm{RR}=$ relative risk.

$\dagger \mathrm{CI}=$ confidence interval.

and SUDAAN (version 7.10; Research Triangle Park Institute, Research Triangle Park, NC). Relative risks (RRs) of seropositivity (Tables 1 and 2) and confirmed infection were calculated for the univariate analyses (Tables 1 and 2) taking into consideration the effect of village cluster sampling. For the multivariate modeling, logistic regression was used to calculate adjusted odds ratios (ORs) to estimate the risk of seropositivity and confirmed infection associated with various village activities.

\section{RESULTS}

Prevalence survey. The overall seroprevalence in the surveyed area was $19.4 \%$ (95\% confidence interval $[\mathrm{CI}]=$ $16.9 \%, 21.8 \%)$. Seroreactive persons were found in all villages. Seroprevalence in individual sites (Figure 1 and Table 1) ranged from $2.5 \%(95 \% \mathrm{CI}=0.06 \%, 13.2 \%)$ to $43.5 \%$ $(95 \%$ CI $=41.0 \%, 46.0 \%)$. High-prevalence foci included Ezo $(37 \%, 95 \% \mathrm{CI}=31.6 \%, 42.5 \%)$ and Source Yubu $(21.5,95 \%$ CI $=19.0 \%, 24.0 \%)$.

With a single field examination, we confirmed infection by identifying trypanosomes in specimens from 173 of the 263 seropositive persons (66\%). Among the seropositive persons in whom parasites were undetected in the initial field examination, infection was confirmed in $85 \%$ of those who received serial follow-up, resulting in an overall confirmation rate of $95 \%$. Trypanosomes were commonly found in lymph node fluid, and infections in most patients (81\%) were confirmed by lymph node puncture. Forty-three (16\%) of the seroreactive survey participants without confirmed infection were lost to follow-up; two (1\%) died before examination was completed. Most participants $(831 ; 61 \%)$ reported having been screened at least once in the past for trypanosomiasis; 31 persons had a history of trypanosomiasis diagnosis and treatment before 1990 . Of these 31 , we found that 21 tested seronegative, nine tested seropositive with confirmed infection, and one tested seropositive but was lost to follow-up. Disease stage was determined for 203 survey participants with trypanosomiasis, and CNS involvement was found in $96(47 \%)$.

Clinical and epidemiologic data. Demographic characteristics of the survey participants reflected the general population (Table 1). Seroprevalence did not differ significantly by sex (19.2\% among females, $19.6 \%$ among males). Children less than 10 years old had a reduced risk of seropositive status $(\mathrm{RR}=0.40,95 \% \mathrm{CI}=0.16,0.98)$ compared with the oldest adult group. Risk of seropositivity was elevated among adults 40-49 years of age. 
TABLE 2

Association between Trypanosoma brucei gambiense seropositivity and routine activities among residents of Tambura County, Sudan, 1997

\begin{tabular}{|c|c|c|c|c|c|c|c|c|}
\hline \multirow[b]{2}{*}{ Activity } & \multicolumn{4}{|c|}{ Done regularly } & \multicolumn{4}{|c|}{ Done where many tsetse flies were present } \\
\hline & Number & $\%$ Seropositive & RR* & $\mathrm{CI} \dagger$ & Number & $\%$ Seropositive & $\mathrm{RR}^{*}$ & $\mathrm{Cl} \dagger$ \\
\hline Collecting water & 1,117 & 19.5 & 1.1 & $0.7,1.5$ & 1,034 & 21.3 & 1.6 & $1.1,2.3$ \\
\hline Farming & 1,149 & 19.4 & 1.0 & $0.7,1.6$ & 926 & 22.6 & 1.8 & $1.4,2.5$ \\
\hline Fishing & 204 & 11.8 & 0.6 & $0.3,9.7$ & 493 & 16.6 & 0.8 & $0.6,1.0$ \\
\hline Collecting firewood & 511 & 17.4 & 0.8 & $0.6,1.1$ & 431 & 21.1 & 1.1 & $0.9,1.5$ \\
\hline Soaking cassava & 145 & 15.2 & 0.8 & $0.4,1.3$ & 245 & 23.3 & 1.2 & $0.9,1.7$ \\
\hline Hunting & 67 & 11.9 & 0.6 & $0.3,1.2$ & 148 & 18.2 & 0.6 & $0.3,1.2$ \\
\hline Going to market & 403 & 16.4 & 0.8 & $0.6,1.1$ & 140 & 16.4 & 0.8 & $0.5,1.4$ \\
\hline Caring for livestock & 11 & 9.1 & 0.5 & $0.1,2.7$ & 11 & 27.3 & 1.4 & $0.5,3.8$ \\
\hline Hiding & 35 & 14.3 & 0.7 & $0.3,1.8$ & 182 & 22.0 & 1.1 & $0.8,1.6$ \\
\hline
\end{tabular}

$* \mathrm{RR}=$ relative risk.

$\dagger \mathrm{CI}=$ confidence interval

Several symptoms reported by study participants were associated with testing seropositive. These included fevers lasting longer than 1 month, myalgias or arthralgias, and facial or peripheral edema (Table 1). Similar associations were seen between these symptoms and confirmed infection. Although fever and arthralgias were associated with both clinical stages of trypanosomiasis, edema was significantly associated only with late-stage disease $(\mathrm{RR}=5.5,95 \% \mathrm{CI}$ $=2.8,11.1$ ).

Trypanosomiasis was associated with daily village activities, but not with behaviors directly related to the civil war. In univariate analysis, seropositive status (Table 2) and confirmed infection were significantly associated with farming and collecting water if these were done in a location where tsetse flies were observed. A reduced risk of seropositivity was observed in persons who fished. Hiding in the nearby forest in response to war-related threats was reported by 182 $(13.6 \%)$ persons surveyed, but it was not associated with serostatus. Fourteen percent of the population surveyed had resided elsewhere for a period of more than one month within the past 3 years. More than $7 \%$ had temporarily fled to Central African Republic or Democratic Republic of Congo (mean duration $=15.5$ months). Seropositivity rates in these groups were not significantly different from the rate in persons who remained at home (Table 2).

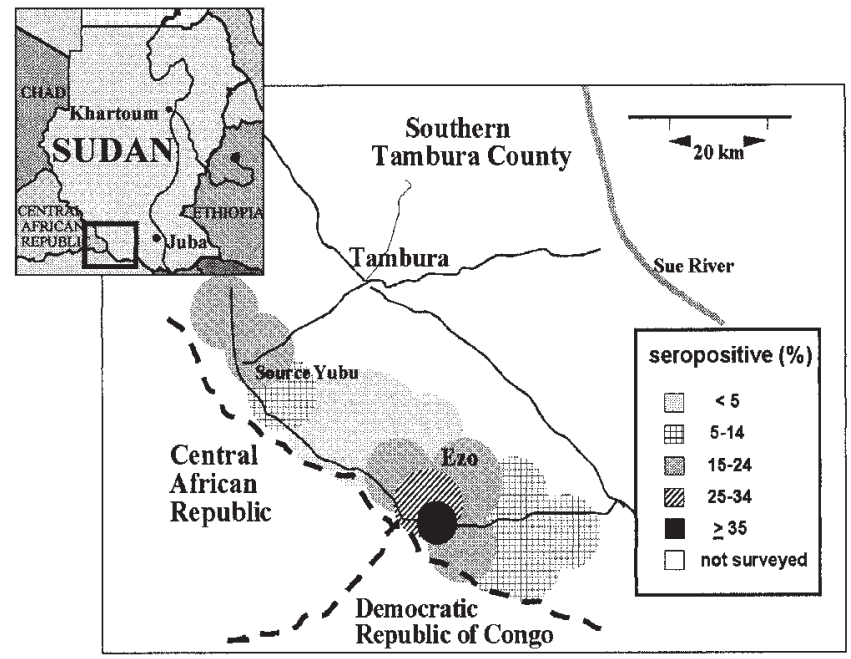

Figure 1. Map of southern Tambura County, Sudan and Trypanosoma brucei gambiense seroprevalence in the survey area.
Using a multivariate linear regression model that adjusted for potential confounding among the various village activities, farming at sites with many flies was the only activity significantly associated with seropositive status $(\mathrm{OR}=1.84$, $95 \% \mathrm{CI}=1.26,2.69)$ or confirmed infection $(\mathrm{OR}=1.95$, $95 \% \mathrm{CI}=1.26,3.03)$. Fishing, if done regularly, was protective (confirmed infection $\mathrm{OR}=0.44,95 \% \mathrm{CI}=\mathrm{CI} 0.25$, 0.76 ), even if done in a location with flies present (confirmed infection $\mathrm{OR}=0.69,95 \% \mathrm{CI}=0.51,0.95)$. Trends were similar in both high- and low-prevalence villages.

\section{DISCUSSION}

Our survey has documented a dramatic resurgence of epidemic sleeping sickness in Tambura County, Sudan. Limited baseline data (Losio E, unpublished data) are available for 13 of our 16 surveyed villages. When population screening was conducted in 1988, trypanosomiasis was found in only 7 of those 13 villages. In 1997, it was present in all of them. Furthermore, since 1988, the overall disease prevalence in those villages increased nearly two orders of magnitude, from $0.3 \%$ to $20.4 \%$. Based on an estimated population of 25,000 in the surveyed area and our finding of $19.4 \%$ seropositivity, we estimate that there may be 5,000 trypanosomiasis cases in the county.

Historically, social upheaval has been a contributing factor in outbreaks of trypanosomiasis. ${ }^{6,7}$ Trypanosomiasis control activities are particularly vulnerable to collapse in settings of civil strife. Furthermore, social disruption often leads to population movements and altered relationships of humans with tsetse habitat. The situation in southern Sudan suggests that here too the civil war was associated with a collapse of the public health infrastructure, which has resulted in this epidemic of trypanosomiasis. However, we were unable to demonstrate an association of infection in Tambura residents with behavioral risk factors that were directly related to the war. We observed that within the surveyed area, the microfoci with the highest prevalence were exactly the same ones identified in previous epidemics. The endurance of these foci may be due to ecologic characteristics of these sites favorable for tsetse breeding and human-fly contact. Our survey could not determine whether infections introduced into the area by transient residents during the previous decade contributed to the resurgence of the disease. However, the previous control program of active case detection and treatment did not complete- 
ly eliminate trypanosomiasis from these foci. At the time control activities collapsed, prevalence levels in these locations were $0.1-0.5 \%$ (Losio E, unpublished data). The absence of any trypanosomiasis surveillance or available treatment for nearly a decade is certainly an important factor in the current resurgence of the disease in Tambura County. Similar trends were documented in endemic areas of the former Zaire, where an 80-fold increase in the incidence of trypanosomiasis occurred in some areas after control measures were interrupted for six years during the 1960s. ${ }^{6}$

As expected, ${ }^{7}$ we found infection to be associated with routine village activities in which there is contact with Glossina fuscipes fuscipes, the vector species found in Tambura. However, the survey had insufficient statistical power to identify specific transmission sites within villages. Risks of infection associated with farming and water collection were increased, but only farming reached statistical significance. The protection against infection afforded by fishing may result from use of fishing sites removed from the villages and fewer hours spent farming. The risk of trypanosomiasis was also reduced in persons who resided away from home for more than one month, regardless of destination. It is likely that most travelers, including those who fled to adjacent countries, spent less time in higher risk domestic activities while away from home, even if the trips were prolonged.

Limitations of our methods may cause the trypanosomiasis prevalence measured in our survey to be somewhat higher than the true disease prevalence. Information about the demographics and population in southern Tambura County was scanty at the time of the survey. Because the number of people governed by each headman was unknown, some sectors may have been incompletely sampled. Furthermore, the 1996 census data used in the survey probably overestimated the population of Ezo, causing us to oversample in a high prevalence area. Recent data suggest the population of Ezo is only about one-third of the number used in our survey. If so, weighting our data using revised population estimates for Ezo would reduce the overall trypanosomiasis seroprevalence in the surveyed area from $19.4 \%$ to $14.5 \%$.

Our survey was conducted at a time when the incidence of trypanosomiasis in Tambura County appears to have been increasing rapidly. Early-stage sleeping sickness was diagnosed in more than half of the infected survey participants, and these persons most likely had acquired their illness during the previous year. Untreated, T. b. gambiense infection is fatal within a few years. In response to the alarming infection prevalence levels and the apparently high incidence rate, IMC and CARE International have implemented a control program of population screening and case treatment. As an adjunct measure, Medical Emergency Relief International placed focused vector control in the surveyed area.

Unfortunately, the resurgence of trypanosomiasis in southern Sudan does not appear to be limited to Ezo and its environs. Ongoing active surveillance and convenience sampling have recently found seroprevalences of 10-30\% in historically endemic villages elsewhere in Tambura County and Western Equatoria (Richer M, unpublished data). Furthermore, anecdotal reports from Tambura residents suggest that epidemic trypanosomiasis is threatening neighboring communities in Central African Republic.

Human African trypanosomiasis can be effectively con- trolled with systematic active case detection, through periodic population screening, followed by treatment of infected persons. However, conflict, civil disruption, and diminishing health budgets have limited both surveillance programs and available treatment in many trypanosomiasis-endemic foci. As a result, the infection has re-emerged as a leading public health problem in the central African region. The number of reported cases in Democratic Republic of Congo and Angola have markedly increased in recent years to historic levels, even though only a fraction of the population at risk is under surveillance. The annual incidence in sub-Saharan Africa is estimated by the World Health Organization to be 300,000. When World Bank calculations ${ }^{8}$ are extrapolated to account for the estimated number of current cases, trypanosomiasis results in 10 million disability-adjusted life years lost, placing it second only to malaria in the global burden of parasitic disease. ${ }^{8}$ Obtaining adequate resources to maintain active surveillance in $T$. b. gambiense-endemic areas and to reestablish abandoned control programs will remain a challenge. However, the current cost of implementing these programs is insignificant compared with the future cost of delayed interventions to contain this expanding epidemic.

Acknowledgements: We thank the following persons for their technical assistance: Betty Awuor, Tito Musa, Helen Small, John Baptist, and William Buko (CARE), and Allen Hightower (Centers for Disease Control and Prevention). We also thank Mary Bartlett, Dennis Juranek, and Tom Navin for thoughtful reviews of the manuscript.

Financial support: This survey was funded by CARE, International.

Authors' addresses: Anne Moore, Jacquelin Roberts, and Deborah Levy, Division of Parasitic Diseases, Centers for Disease Control and Prevention, Mailstop F-22, 4770 Buford Highway, Atlanta, GA 30341-3724. Michaleen Richer and Edward Losio, International Medical Corps, PO Box 67513, Central Place, Nairobi, Kenya. Mario Enrile, CARE Somalia/South Sudan, PO Box 43864, Nairobi, Kenya.

\section{REFERENCES}

1. Ekwanzala M, Pepin J, Khonde N, Molisho S, Bruneel H, De Wais P, 1996. In the heart of darkness: sleeping sickness in Zaire. Lancet 348: 1427-1430.

2. World Health Organization, 1998. Control and surveillance of African trypanosomiasis. World Health Organ Tech Rep Ser 881 .

3. Paquet C, Castilla J, Mulamberi D, Beaulieu M, Gasteelu-Etchegorry M, Moren A, 1995. La trypanosomiase a Trypanosoma brucei gambiense dans le foyer du nor-oest de l'Ouganda. Bilan de 5 annees de lutte (1987-1991). Bull Soc Pathol Exot 88: $38-41$

4. Molyneux DH, 1996. Current public health status of the trypanosomiases and leishmaniases. Hide G, Mottram JC, Coombs GH, Holmes PH, eds. Trypanosomiasis and Leishmaniasis, Wallingford, United Kingdom: CAB International, 39-50.

5. Turner A, Magnani R, Shuaib M, 1996. A not quite as quick but much cleaner alternative to the Expanded Programme on Immunization (EPI) cluster survey design. Int J Epidemiol 25: 198-203.

6. Ruppol JF, Libala K, 1977. Situation actuelle de la lutte contre la maladie du sommeil au Zaire. Ann Soc Belg Med Trop 57: 299-314.

7. Scott, D, 1970. The epidemiology of Gambian sleeping sickness. Mulligan HW, Potts WH, eds. The African Trypanosomiases. London: George Allen and Unwin, 614-644.

8. World Development Report, 1993. Investing in Health. The World Bank. New York: Oxford University Press, 216-219. 